\title{
Students' Positioning in the Classroom: a Study of Teacher-Student Interactions in a Socioscientific Issue Context
}

\author{
Ulrika Bossér $^{1}$ (D) Mats Lindahl ${ }^{1}$
}

Published online: 18 July 2017

(C) The Author(s) 2017. This article is published with open access at Springerlink.com

\begin{abstract}
The integration of socioscientific issues (SSI) in science education calls for emphasizing dialogic classroom practices that include students' views together with multiple sources of knowledge and diverse perspectives on the issues. Such classroom practices aim to empower students to participate in decision-making on SSI. This can be accomplished by enhancing their independence as learners and positioning them as legitimate participants in societal discussions. However, this is a complex task for science teachers. In this study, we introduce positioning theory as a lens to analyse classroom discourse on SSI in order to enhance our knowledge of the manners by which teachers' interactions with students make available or promote different positions for the students, that is, different parts for the students to play as participants, when dealing with SSI in the classroom. Transcripts of interactions between one teacher and six student groups, recorded during two lessons, were analysed with respect to the positioning of the students as participants in the classroom, and in relation to the SSI under consideration. The results show that the teacher-student interactions made available contrasting student positions. The students were positioned by the teacher or positioned themselves as independent learners or as dependent on the teacher. Furthermore, the students were positioned as affected by the issue but as spectators to public negotiations of the issue. Knowledge about the manner in which teacher-student interactions can function to position students seems important for dialogic classroom practices and the promotion of student positions that sustain the pursuit of intended educational outcomes.
\end{abstract}

Keywords Classroom discourse $\cdot$ Teacher-student interactions · Positioning theory · Socioscientific issues $\cdot$ Climate change

Ulrika Bossér

ulrika.bosser@lnu.se

1 Department of Chemistry and Biomedical sciences, Linnaeus University, S-39182 Kalmar, Sweden 


\section{Introduction}

Contemporary societies are characterized by an abundance of information, disputed knowledge claims and new technologies. Besides providing solutions to problems, scientific and technological progress often gives rise to new uncertainties and risks, and raises a wide range of societal, political and economic concerns alongside ethical dilemmas. In view of this, an important aim of science education is to prepare students for informed decision-making and action in relation to these societal dilemmas associated with scientific and technological developments, often termed socioscientific issues or SSI (Ratcliffe and Grace 2003). The aim to prepare students for decision-making and action in relation to SSI challenges are prevailing approaches to science education, whereby the teacher is typically positioned as the conveyor of established scientific knowledge (Sadler 2009). Prevailing approaches to science education are also challenged since many students today find school science irrelevant and insignificant for their lives (Aikenhead 2006; Jenkins 2006; Lyons 2006). Many students say that they would like to deal with contemporary science-related issues in their science classes (Jenkins 2006). They also say that existent transmissive pedagogy does not provide sufficient opportunities for them to engage in discussions and inquiry out of their own interest (Jenkins 2006; Lyons 2006).

The integration of SSI into science education is one response to the challenges described above. Dealing with SSI in the science classroom has been shown to provide students with opportunities to develop content knowledge (Klosterman and Sadler 2010) as well as moral and ethical sensitivity (Fowler et al. 2009; Lee et al. 2013), and to provide students with opportunities to practice higher-order thinking (Sadler 2009), which is vital to informed decision-making and action in relation to SSI. Moreover, research indicates that it can improve students' interest and motivation (Harris and Ratcliffe 2005; Ottander and Ekborg 2012; Sadler 2009). Dialogic (Nystrand 1997; Scott 1998; Wells 2007) classroom practices, in which students' contributions are valued, are emphasized in order to provide students with opportunities to express and reflect on their own perspectives on SSI and those of others (Ratcliffe and Grace 2003; Zeidler et al. 2005). Such classroom practices also aim to empower students in terms of enhancing their independence as learners (Zeidler et al. 2011) and positioning them as "legitimate participants" in discussions and decision-making on SSI, both inside and outside the classroom (Sadler 2009). At the same time, the advancement of such dialogic classroom practices places new demands on science teachers; however, detailed knowledge of how teachers might manage classroom discourse when dealing with SSI is lacking. In the present study, positioning theory (Davies and Harré 1990; Harré and van Langenhove 1999; Harré and Moghaddam 2003) is used as a framework to analyse verbal interactions between one teacher and six student groups, recorded during two consecutive lessons, regarding a specific SSI. The aim is to provide knowledge of the ways in which teachers' interactions with students make available or promote different student positions, or different parts for the students to play as participants, when dealing with SSI in the classroom.

\section{Background}

\section{Arguments for Emphasizing Dialogic Classroom Practices when Dealing with SSI}

SSI are typically value-laden, contentious and subject to multiple interpretations. Thus, dealing with SSI in the classroom offers opportunities for dialogic classroom practices in which 
students examine and evaluate multiple sources of knowledge and diverse perspectives through social interactions, such as group and whole-class discussions and debates (Ratcliffe and Grace 2003; Zeidler et al. 2005). Specifically, dealing with SSI calls for recognizing the students' perspectives on the issues. This is because, for people of various ages and levels of education, from primary school pupils (Byrne et al. 2014) to high school students (Patronis et al. 1999), university students (Sadler and Zeidler 2004), and university professors and research assistants (Bell and Lederman 2003), decisions on SSI are often influenced by moral, personal and social considerations. Furthermore, recognition of students' perspectives on SSI is important if we agree that "science education ought to encourage learners to develop a sense of having something to say about these issues and to see themselves as legitimate participants in social dialogues, particularly those which involve science" (Sadler 2009, p. 12-13).

Such dialogic classroom practices that recognize students' perspectives and engage them in an interactive way provide students with the opportunity to relate the learning activities to their personal experiences and prior knowledge, thereby connecting school science and the students' life-worlds. It responds to the aforementioned criticism of predominant transmissive pedagogy in science education, and there is some evidence that it makes school science engaging and more relevant to students (Aikenhead 2006; Harris and Ratcliffe 2005; Osborne et al. 2002). Research conducted in diverse fields of education, such as literature (Nystrand 1997), science (Almahrouqi and Scott 2012) and mathematics (Kyriacou and Issitt 2008), has also shown that, strategically used, dialogic classroom practices have the potential to enhance learning outcomes, conceivably due to the possibility for students to encounter and deal with various explanations and perspectives. Specifically, dialogic classroom practices that provide students with opportunities to examine multiple perspectives have been shown to promote reasoning skills and critical thinking abilities vital to informed decision-making and action in relation to value-loaded SSI (Frijters et al. 2008). Thus, they are suitable to prepare students for active citizenship.

\section{New Demands on Teachers Associated with the Advancement of Dialogic Classroom Practices}

The advancement of dialogic classroom practices places a number of new demands on science teachers. Sometimes, students are not keen to share their opinions in class (France et al. 2012), and teachers have reported that often only a limited number of students actively participate in discussions on SSI (Bossér et al. 2015). Consequently, teachers have to establish a classroom environment that encourages students to voice their opinions in discussions on SSI. For example, it has been suggested that teachers should manage classroom discourse in a way that facilitates students relating to the issue under consideration on a personal level (Bossér et al. 2015). Moreover, emotive reasoning grounded in empathy and sympathy with other people plays a significant part in decision-making on SSI (Sadler and Zeidler 2004, 2005), and students' expressions of emotions in the classroom are common, for example, in relation to serious global issues (Ojala 2015). Consequently, it is important that teachers also have strategies to deal with emotions expressed in the classroom when using SSI as contexts for science teaching. Specifically, research indicates that teachers' recognition of negative emotions, such as worry or anger, alongside classroom discussions involving solution-oriented and positive views of the future, are vital for the promotion of students' empowerment vis-á-vis their perceptions of their potential to influence their own lives and actively engage with serious issues (Ojala 2015). 
However, it is a challenging task for many science teachers to meet these new demands in order to advance more dialogic classroom practices (Ratcliffe and Millar 2009). Specifically, many science teachers lack distinct teaching strategies to manage discussions (Bryce and Gray 2004; Newton et al. 1999), particularly concerning value-laden issues (Levinson 2004). It has also been reported that teachers find it difficult to manage classroom discourse that promotes students' independence as learners, allowing them to explore their own perspectives, while pursuing intended learning goals in terms of a predefined body of content knowledge (Bossér et al. 2015). In addition, teachers are sometimes hesitant or lack the confidence to deal with emotions that may arise in relation to SSI (Bryce and Gray 2004). In view of these challenges, it is perhaps not remarkable that talk in science classrooms is typically dominated and controlled by the teacher (Lemke 1990; Newton et al. 1999; Osborne et al. 2002; Pimentel and McNeill 2013). The students' perspectives on the issues are usually insufficiently recognized, since the teachers generally ask the majority of questions, and the questions are not typically asked to convey the students' thinking but have "pre-specified" answers (Lemke 1990).

\section{Research on Teacher-Student Interactions Regarding SSI}

While there are a number of detailed analyses of teacher-student interactions in the science classroom, concerned with the teaching of science content (Chin 2006; Lemke 1990; Mortimer and Scott 2003; van Zee and Minstrell 1997; Wellington and Osborne 2001) and argumentation skills (Dawson and Venville 2008; Mork 2005; Simon et al. 2006), only a few studies deal with moment-to-moment teacher-student interactions regarding SSI. Levinson (2004) performed a classroom study on student-student and teacher-student interactions on ethical issues related to biotechnology. His analysis revealed that, although open dialogue of ethical issues was an objective of the lessons, the ethical debate was inhibited by the teacher's interventions, and the teacher failed to elicit the students' perspectives when intervening in group discussions. Another study by Pimentel and McNeill (2013) investigated five teachers' management of discussions during the teaching of an ecology unit, wherein one lesson was aimed at eliciting students' views on climate change. The authors concluded that the teachers' moves during the discussions often constrained the students' expressions of their reasoning and their perspectives on the issue. Thus, these studies further point to the complexity of managing classroom discourse that is aimed at recognizing students' perspectives and positioning students as legitimate participants in dialogue and decision-making on SSI. Yet, more research is needed in order to provide substantial knowledge on the ways in which teachers' management of classroom talk can promote the pursuit of this aim. In the following section, we present the literature that guides our analysis of teacher-student interactions with respect to the positioning of students in the SSI classroom.

\section{Positioning Theory}

Positioning, as described by Harré and colleagues (Davies and Harré 1990; Harré and van Langenhove 1999; Harré and Moghaddam 2003), can be understood as participants in interactions taking up or being assigned fluid parts to play in relation to different "storylines", that is, different realms of interpretation of what is being played out in the specific situation. A storyline provides a certain space for action in that it makes available certain positions or parts for the participants to perform. It is important to note that positions are dynamic and often change as an interaction proceeds. A position carries expectations and constraints, as well as 
responsibilities and rights. For example, as illustrated by Davies and Harré (1990), if a participant interprets a storyline being realized in a situation as "medical treatment", then nurse and patient become positions associated with that storyline, and these positions carries responsibilities and rights, such as the nurse's responsibility to provide care and the patient's right to be given care. In any situation, a range of storylines are available for the participants to draw on (Davies and Harré 1990). The storylines are often derived from the historical context of a practice and the participants' experience of that practice (Harré and van Langenhove 1999). Consequently, a repertoire of storylines is often shared within a community of practice.

As manifested in the example above, positions reflect relationships. Thus, when somebody involved in a conversation positions him- or herself (reflexive positioning), he or she simultaneously positions the other (interactive positioning) and vice versa (Davies and Harré 1990; Harré and van Langenhove 1999; Harré and Moghaddam 2003). In a conversation, the initial act of positioning that introduces a certain storyline is called first order positioning. First order positioning is often tacit, and participants in a conversation are often not even aware of it. If the first order positioning is subsequently questioned by one of the participants in the conversation, as he or she does not accept the storyline introduced in the first order positioning, it is called second order positioning (Harré and van Langenhove 1999). Second order positioning is always intentional and implies that the storyline "will shift from its original object to the story itself" (Harré and van Langenhove 1999, p. 20), which provides opportunities to negotiate relationships and potentially offers alternative positions. Positioning through talk is accomplished through, for example, the use of personal pronouns, modality, use of the active or passive voice and whether a person is talked about as an agent or an object of an action, i.e. if things are done by a person or to a person (Wood and Kroger 2000).

As described previously, a range of storylines are available for participants in an interaction to draw on in any situation. Thus, when dealing with SSI in the science classroom, there is a repertoire of storylines available for teachers and students to draw on. For example, there is the pervasive "storyline of instruction" (Harré and van Langenhove 1999, p. 17), in which the teacher is typically positioned as a conveyer of content knowledge (Sadler 2009), and the students correspondingly as recipients expected to recall that knowledge. However, many SSI are controversial, which means that contrary, yet well-reasoned, views could be held on the issues. Hence, the teacher cannot provide all the answers in discussions on SSI (Hand and Levinson 2012). Consequently, SSI offer opportunities for the teacher and the students to be positioned in alternative ways compared to conveyor and recipients of knowledge. We, therefore, assume that dealing with SSI in the science classroom will offer a new educational experience with opportunities to follow new storylines that make available new positions for the students. Moreover, in any classroom, there are storylines available that position the students and the teacher in relation to the content under consideration and to the larger society (Östman 1998). Therefore, when dealing with SSI, it is relevant to consider how different storylines make available different positions for the students in relation to the issues, that is, how different storylines potentially offer different parts for the students to play in relation to SSI.

Because positions are always relational, teachers position students through teaching and thereby influence students' access to certain spaces for action. For example, a teacher might enact a storyline that either invites or discourages student contributions and thereby influence the students' access to certain spaces for action, such as participation in classroom discussions. Research indicates that teachers' recognition of the value of students' contributions promotes students' engagement and participation in classroom discourse (Nystrand 1997; Smith and Higgins 2006). Recognition of students' contributions can be accomplished through, for example, the teacher allowing students' contributions to modify the course of the interactions 
in some way, by incorporating students' ideas into subsequent discussions and elaborating on new perspectives put forward by a student (Nystrand 1997). Thereby, the students are positioned as legitimate contributors to classroom discourse, which is an important condition for the advancement of dialogic classroom practices (Nystrand 1997; Scott 1998; Wells 2007).

\section{Research Aim}

The aim of the present study is to enhance our knowledge of the ways in which teachers' interactions with students can make available or promote different positions for the students, that is, different parts for the students to play as participants, when dealing with SSI in the classroom. Teacher-student interactions involving a teacher who has acquired theoretical knowledge of the use of SSI in science teaching and whose aim is to enhance student participation and independence are analysed with respect to the positioning of the students. Specifically, it is investigated how the students are positioned by the teacher and how they position themselves (a) as participants in the classroom practice and (b) in relation to the issue under consideration.

\section{Method}

\section{Participants}

The setting of this research project was a public upper secondary school in a small Swedish city. A science teacher who was involved in implementing SSI throughout an academic year (about $90 \mathrm{~h}$ of instructional time) and his 15-16-year-old students (a total of 32 students) in the "Social Science Program" (preparatory for higher education) participated in the study. At the time of the study, the students had no prior experience of working with SSI. They were invited to participate in accordance with Swedish ethical guidelines (The Swedish Research Council 2011). Thus, the students were informed about the overall purpose of the research and that their participation in the study was voluntary. They were given guaranties of anonymity and were informed that they could withdraw from the study at any time, i.e. declining to be recorded. Written approvals were obtained from all of the students.

At the time of the study, the participating teacher had 10 years of teaching experience. Before the start of this research project, he had participated in a 15 ECTS $^{1}$ university course for practicing teachers on the use of SSI in science education. The university course included planning lesson themes in accordance with the upper secondary school curriculum, and the primary source of course literature was Zeidler (2003). After finishing the university course, the teacher decided to integrate SSI into his science teaching and was therefore invited to participate in this research project.

\section{Context of the Study}

The study was situated in the "Science Studies" course which is compulsory for all non-science bound students in the Swedish upper secondary school. Some of the aims of "Science Studies" are that the students "develop an understanding of how scientific knowledge can be used in both

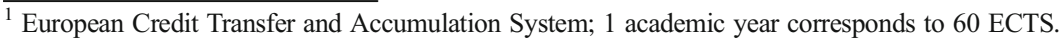


professional life and everyday situations", and that students are enabled "to make personal choices and form their views". By taking part in discussions on societal issues related to science, students should also get an opportunity to develop their science knowledge "to be able to meet, understand and influence their own contemporary conditions" (Skolverket 2011, p. 1).

The study comprises a unit on climate change in which the students were assigned the task of designing societies on small, fictitious islands in the Baltic Sea. They should make decisions on how to reduce the net carbon dioxide emissions of the societies to zero, and how to adapt the societies to the potential future consequences of climate change. In an interview, prior to carrying out the unit, the teacher expressed that his aim was to enhance the students' activity and promote their independence as learners. Based on relevant information, they acquired on their own, the students were supposed to suggest actions to be taken in response to climate change, while balancing ecological, social and economic demands. The particular unit was chosen because it was the students' first experience of working with SSI. It was therefore assumed that positions would be negotiated in the classroom due to this new educational experience which would offer opportunities to investigate how a teacher might manage classroom discourse while implementing SSI. The particular sequence of lessons was chosen due to the relatively large proportion of teacher-student conversations during the lessons. The sequence of lessons was introduced by a 6-min film in which a climate researcher speaks about what recent scientific modelling and interpretations of climate data indicate regarding the presumed development of the average temperature on Earth. In the film, the researcher concludes that the temperature on Earth will inevitably rise at least $2{ }^{\circ} \mathrm{C}$, and that we will need to develop a society with no use of fossil fuels no later than 2050 to prevent further anthropogenic climate change. Specific consequences of a rise in temperature, such as rising water levels, and how changes in water levels and temperature might affect different places on Earth in various ways were not presented in the film. After the class had watched the film, the teacher instructed the students to consider the implications of the conclusions presented in the film for the societies on their islands. The students worked in groups of 5-6 students. Each group had access to a computer with an Internet connection. The teacher guided the students in their group work when they requested guidance.

\section{Data Collection and Analysis}

Data were collected in the form of audio recordings from all six student groups during the first two lessons of the sequence. Consequently, non-verbal aspects of interactions, such as hand gestures and facial expressions, are not included in the analysis. The total time of the recordings was $7 \mathrm{~h} 8 \mathrm{~min}$. In the first lesson, only five groups were recorded due to a technical problem with one of the recording devices. In the second lesson, one of the groups turned off the recording device after $13 \mathrm{~min}$ for unknown reasons. The recordings were transcribed verbatim, and all the segments containing verbal interactions between the teacher and the student groups (approximately 8400 words) were excerpted for further analysis.

First, to investigate students' positioning as participants in the classroom practice, the teacher-student interactions were analysed by paying attention to whether the students or the teacher were talked about as agents of actions in the classroom (Wood and Kroger 2000), to make inferences about presumed rights and responsibilities for the teacher and the students to preliminarily identify and define student positions (Davies and Harré 1990; Harré and van Langenhove 1999; Harré and Moghaddam 2003). Furthermore, all instances in which a student contributed something new to the discussion were identified. Such instances involved 
when students added new information not earlier introduced by the teacher or the film, or expressed viewpoints or emotions regarding the issue. The teacher's responses to such contributions, for example if the teacher recognized the students' contributions by allowing them to modify the course of interaction in some way (Nystrand 1997), were examined. These instances were chosen because, in this particular classroom, the students had the opportunity to initiate conversations with the teacher around topics that they found relevant. Thus, the organization of the classroom talk was already student-centred to a large extent and not controlled primarily by the teacher. Yet, instances in which the students contributed something new to the discussion indicate that the students follow a storyline in which they are allowed to contribute in various ways to classroom discourse, that is, they position themselves as legitimate contributors to classroom discourse. Also, through the teacher's opportunity to recognize or ignore such student contributions, the teacher could either take up or challenge this storyline in which the students are positioned as legitimate contributors to classroom discourse.

Second, the concept of positioning (Davies and Harré 1990; Harré and van Langenhove 1999; Harré and Moghaddam 2003) was used as a lens to investigate how the students were positioned by the teacher and how they positioned themselves in relation to the issue of anthropogenic climate change, that is, how the students claimed or were offered different parts to play in relation to the issue. All passages of the teacher-student interactions that concerned climate change, i.e. the causes and consequences of climate change or actions in response to climate change, were analysed. Attention was paid to pronoun use, the use of active or passive voice and whether the students, the teacher, experts, politicians or others were talked about as agents or objects of actions related to the issue of climate change (Wood and Kroger 2000), to make inferences about students' rights and responsibilities, to preliminarily identify and define student positions.

All the preliminary positions identified in the first and second step of the analysis were subsequently analysed inductively. Commonalities or distinguishing features, such as claimed or assigned rights and responsibilities, were explored in order to identify final themes (Robson 2011), i.e. how the students were positioned by the teacher or positioned themselves in different ways (a) as participants in the classroom practice and (b) in relation to the issue of climate change.

Analyses of segments of dialogue that are representative of the different themes were translated into English and are presented in the Results section to enable readers to judge the credibility of the analyses (Robson 2011). Digressions that are judged irrelevant for the purpose of the analysis are omitted. The following markings are used in the excerpts: /.../ indicates part of the transcript omitted; [notes between square brackets] indicates clarification by the researchers; and ... indicates interruption of speech. The students are given aliases to preserve their anonymity.

\section{Results}

In this section, the final themes that are the result of the analysis are described. First, it is described how the students were positioned by the teacher or positioned themselves as participants in the classroom practice, and, second, a description is provided of how the students were positioned in relation to the issue of climate change. 


\section{Students' Positions as Participants in the Classroom Practice}

\section{Students as Independent Learners}

The teacher repeatedly engaged in the positioning of the students as independent learners, in terms of being able to and responsible for acquiring relevant information and reaching conclusions based on available information on their own, instead of relying on the teacher. Correspondingly, the teacher positioned himself as a facilitator of learning, rather than a conveyor of knowledge. However, this positioning was questioned by several students, which can be seen in the excerpt below.

\begin{tabular}{ll}
\hline Ellen & What's best [to use as a fuel for cars], ethanol or electricity? \\
& $/ \ldots /$ \\
Teacher & That is a good thing to investigate, isn't it? \\
Erik & Yes, but we ask you, you're the one who ... [lesson 1, group 5, 5:38] \\
\hline
\end{tabular}

By not answering Ellen's question, the teacher does not take up the storyline that the student introduces, in which the teacher is positioned as an expert and a conveyor of knowledge. Instead, the teacher suggests that the students investigate the issue. This is an instance of second order positioning which initiates negotiation of teacher-student positions. The teacher introduces a new storyline in which he is positioned as a facilitator and the students as responsible for finding relevant information. Erik's objection, "you're the one who", denotes that he challenges the teacher's position as a facilitator, adhering to the storyline of classroom practice, in which the teacher is positioned as the expert and conveyor of knowledge, while the students are correspondingly positioned as recipients.

\section{Students as Legitimate Contributors to Classroom Discourse}

The identification of instances in which the students contributed something new to classroom discourse indicated that in these teacher-student interactions, the students adhered to a storyline in which they are allowed to contribute in various ways to classroom discourse, that is, they positioned themselves as legitimate contributors to classroom discourse. The analysis of all these instances revealed that by recognizing such student contributions the teacher followed this storyline of classroom practice in which the students are positioned as legitimate contributors to classroom discourse. The teacher recognized the students' contributions by modifying the course of interaction in response to them. As will be illustrated by the excerpts below, the teacher modified the course of interaction in response to the students' contributions in two different ways: first, by incorporating into classroom discourse new dimensions of the issue that the students brought forward and second, by changing the focus of the conversation in response to students' expressions of negative emotions regarding the issue.

The students occasionally brought forward new dimensions of the issue of climate change, not introduced by the teacher or in the introductory film. The teacher recognized the importance of such contributions by incorporating these new dimensions into the classroom discourse, as illustrated by the excerpt below. In the excerpt, the students speak of the uncertainty that exists regarding the specific consequences of climate change, adding uncertain knowledge as an obstacle when deciding on actions to be taken in response to those consequences. 
Sophie But then [if the temperature rises two degrees] it may be that we either have [a climate] as Italy

Teacher yes

Sophie yes, or it could be the opposite, that the Gulf Stream turns the other direction so that there's an ice age

Teacher yes

Anne Should we consider both possibilities or what should happen?

Teacher It's possible that that the Earth gets so much warmer that there will be no ice age, but just get a bit cold; this is really complicated and it's possible to, I mean the researchers construct (inaudible), they construct models and we don't know this for sure

Anne No, because we don't know what will happen

Sophie So what should we assume?

Teacher That you don't know

l.../

Anne So we should think that anything could actually happen?

Teacher Maybe you have to consider both options [lesson 2, group 1, 51:25]

In this conversation, the students point out the element of uncertainty of the specific consequences of climate change by arguing that we will either "have as Italy", which from a Swedish perspective means a warmer climate, or, if the Gulf Stream is affected, "there's an ice age", in other words, a considerably colder climate. The teacher recognizes the students' contribution by relating it to the current scientific knowledge base and confirms its validity by taking the dimension of uncertainty up into the classroom discourse. It should also be noted that the students seem to follow a storyline of instruction in which the teacher is positioned as responsible for making decisions for them on how to proceed. The teacher does not completely reject this storyline. However, because the teacher does not simplify the task, this could be considered as an instance of second order positioning in which teacher-student positions are negotiated. The teacher shows that the students are expected to draw conclusions based on the information they have at hand. These expectations align with the storyline of classroom practice in which the students are positioned as independent learners, as described in the previous section.

Some students voiced anxieties regarding how they might suffer personally from the consequences of climate change. Others expressed frustration with the slow pace of action in response to the problem of anthropogenic climate change. The teacher recognized such expressions of negative emotions by changing the focus of the conversation towards positive societal development, which will be illustrated by the following two excerpts. The first excerpt provides an example of how the teacher recognized one student's expression of anxiety. Preceding the excerpt, the conversation between the teacher and the student group concerned the urgency of reducing $\mathrm{CO}_{2}$ emissions and phasing out fossil fuels, put forward by the climate researcher in the introductory film.

Linda I'm really afraid of it [that Earth will perish]

Teacher I don't think you have to be, but we must of course deal with this l.../

Teacher and what he [the climate researcher] said here [in the film] is that there is potential, you saw at the end, he said how much was going on in the world, right? They have initiated a project like a ... like almost like the Apollo. Apollo, you know, it was when they flew to the moon, then they made a lot of resources so that they could get to the moon, and now they put together a kind of project for the Felicia mm whole world to be able to cope with all this, right?

Teacher so many, many researchers are working on this and many, many politicians also work /.../ to be able to reach agreement on how to deal with the carbon dioxide emissions, so work is going on in many, many ways around the world [lesson 1, group 4, 11:49] 
Through the utterance, "I'm really afraid of it", Linda expresses considerable anxiety, possibly proposed by the serious message communicated in the film. In response to her anxiety, the teacher first expresses some comforting words. He then alters the focus of the conversation. Initially, the teacher-student conversation concerned the problems and challenges associated with global warming, put forward by the climate researcher in the film. After the student's expression of anxiety, the teacher alters the focus of the conversation by emphasizing the worldwide efforts by scientists and politicians to reduce $\mathrm{CO}_{2}$ emissions and deal with the consequences of global warming, described at the end of the film. To further emphasize the message, he reiterates the climate researcher's comparison between today's worldwide efforts to reduce climate change and deal with its effects and the Apollo project. The resources invested in the Apollo project resulted in the first landing on the moon. When the teacher makes this comparison, it is thus reasonable to believe that he wants the students to envisage that the resources invested by researchers and politicians to deal with global warming will contribute to solving the problem.

As mentioned above, some students also expressed deep frustration with the slow pace of action in response to the challenge of climate change. The second excerpt illustrates how the teacher responds to one student's expressed frustration.

\footnotetext{
Sophie but it feels like nothing ever gets done, like, a few years ago, there was like a lot about that you should take the bus and that it should be for free so that not so many people would drive a car, but nothing of that has come about; it's even more expensive to take the bus now

Teacher $/ . . /$ there are many solutions but what is ne... /.../ What is news?

/.../[a long discussion of headlines and news feeds follows]

Teacher good things that are being built, they are built up slowly, they don't cause any headlines, but suddenly it breaks through, right? And that can be ... and the thing is that there are very many examples around the world that the newspapers don't write about every day /.../ now I'm just going to tell you that now you should skip to Facebook and you'll find "Good news magazine"; then you like them and you've access to good news, they're on Facebook [lesson 2, group 1, 25:15]
}

Sophie speaks from her own experience and says that "nothing ever gets done" and "nothing of that has come about", which reveals her frustration with the slow pace of action. Although it seems like Sophie's interpretation is overlooked by the teacher, he recognizes her frustration by emphasizing "good news", thereby changing the focus of conversation towards positive societal development to relieve her frustration.

\section{Students as Dependent on the Teacher and as Recipients of Information}

It was noted that, although the teacher repeatedly engaged in the positioning of students as independent learners and legitimate contributors to classroom discourse, the teacher was simultaneously repeatedly positioned as an authority in the classroom, either reflexively or interactively. In these instances, the students were thereby correspondingly positioned as dependent on the teacher and as the recipients of information. This manifested in, for example, the teacher directing the students' work through the use of instructional questions to which he obviously had the answer, and providing explanations and conveying information when the students requested it or when he seemed to find it necessary. Such instances appeared to represent customary teacher-student interaction patterns because no second order positioning occurred, as can be seen in the excerpt below. 
Linda What are net emissions?

Teacher Well, it is like this, you learned when we looked through the carbon cycle, ah, that plants take in carbon dioxide to use in photosynthesis /.../ [explanation continues; lesson 1, group 4, 9:40]

Here, Linda requests an explanation of the scientific concept "net emission" that was used by the climate researcher in the introductory film. She introduces a storyline in which the teacher is positioned as an expert and responsible for conveying knowledge and, correspondingly, the students are positioned as dependent on the teacher and as recipients. The teacher takes up the storyline introduced by Linda, in which he is positioned as an expert and a conveyor of knowledge, by providing the explanation she requested.

\section{Students' Positions in Relation to the Issue of Climate Change}

\section{Students as Members of a Society Responsible for and Affected by Climate Change}

As already illustrated above, some students voiced anxieties regarding how they might suffer personally from the consequences of climate change, that is, they positioned themselves as members of society affected by climate change. At the same time, the teacher repeatedly positioned himself and the students as members of society who share the responsibility and concern for the causes and consequences of climate change, which is illustrated by the excerpts in this paragraph. The first excerpt is derived from a continuation of the teacher's explanation of "net emission", presented previously.

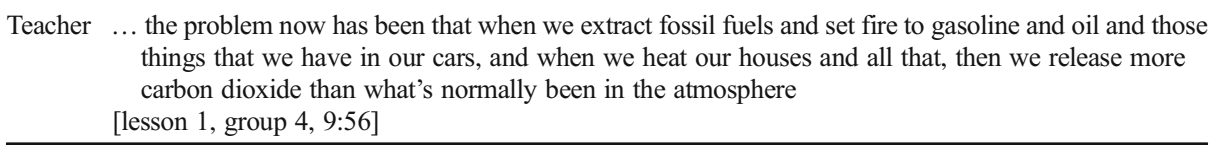

In the first part of the excerpt, "when we extract fossil fuels", the teacher uses the first-person plural "we" in an inclusive way (it includes the ones addressed), but in a very general sense, thus referring to humanity. In the last part of the excerpt, the teacher also uses the first-person plural "we" in an inclusive way, but by referring to "our cars" and "our houses", he positions himself and the students as members of a community jointly responsible for the emissions causing global warming.

After the teacher's explanation, the conversation continues with a brief discussion about the scope of the use of electric motors. The teacher emphasizes that climate change will force technical development and explains, "This will put pressure on the entire society. We have to phase out gasoline engines" [lesson 1, group 4, 11.03]. The teacher's use of "we" in the inclusive way in conjunction with "the entire society" now positions himself and the students as members of a society affected by and jointly responsible for taking action in response to climate change. The teacher's positioning of himself and the students as members of society is further illustrated by the excerpt below. Preceding the excerpt, the student group discussed how to manage both transportation and food production without using fossil fuels. The students showed knowledge of various renewable fuels, but wondered whether there exist boats that run on such fuels. The students called for the teacher's attention to ask him to clarify the issue.

Teacher I'm not an expert on this and when it comes to these kinds of (inaudible) things one can never be an expert and you'll never be science experts, but you must be able to find out things regarding society [lesson 1, group 3, 15:30] 
Here, the teacher refers to himself as not being an expert. This is an instance of reflexive positioning in which he speaks like any citizen, a layperson. The subsequent shift from speaking of himself, "I", to people in general, "one", to the students, "you", implies relationships of equal status. Thus, as members of society, the teacher and the students are equally concerned by these kinds of urgent issues.

\section{Students as Spectators to Public Debate and Decision-Making Regarding Climate Change}

While the students positioned themselves and were positioned by the teacher as members of a society jointly responsible for and affected by climate change, they were not positioned as participants in public debate in relation to the issue. Instead, the students were positioned as spectators, as illustrated by the excerpts below.

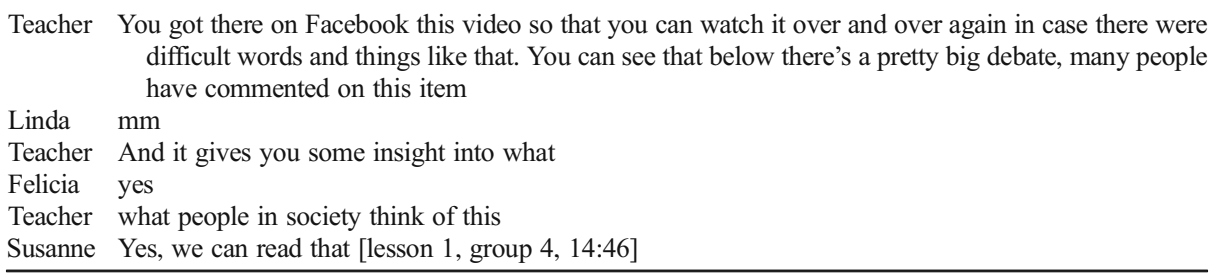

Whereas, the teacher points out that there is a large debate about climate change that many people in society are involved in, he says that following this debate will help students gain "insight into" people's views on the issue. Thereby, the teacher positions these other people outside the classroom as the participants, the agents, in this debate. Correspondingly, the students are implicitly positioned as spectators.

In the same way, the students were positioned as spectators to decision-making and action in relation to the issue, while experts and politicians were positioned as agents responsible for change. For example, when ending the discussion about the uncertainty that exists regarding the specific consequences of climate change, reported on above, the teacher expressed that "this is reality for all the politicians who must make plans for our communities" [lesson 2, group 1, 52:02]. Here, "the politicians" are positioned as the agents who "make plans".

The students also positioned others as responsible for action in relation to the issue, which, for example, is manifested in Sophie's expression of frustration reported on earlier by her use of the passive voice when she complains that "nothing ever gets done" and "nothing /.../ has come about" [lesson 2, group 1, 25:15].

\section{Discussion}

The results from the analysis reveal that a range of storylines was drawn upon in the classroom discourse that made available different positions for the students. Below, we will first discuss storylines that are relevant to how the students are positioned as participants in the classroom practice. Second, storylines relevant to how the students are positioned as participants in negotiations on SSI will be discussed. 


\section{Storylines Relevant to Students' Positions as Participants in the Classroom Practice}

A number of contrasting storylines relevant to the students' positions as participants in the classroom were drawn upon in the teacher--student interactions. Below, contrasting storylines adhered to by the teacher will be discussed in relation to different educational aims associated with the integration of SSI. This will be followed by a discussion of the storylines adhered to by the students.

\section{Contrasting Storylines Regarding Students as Participants Adhered to by the Teacher}

The results show that the teacher adhered to contrasting storylines that made available different positions for the students as participants in the classroom practice. On one hand, the teacher repeatedly drew on a storyline that was aligned with the aim of advancing dialogic classroom practices in which the students were positioned as independent learners and as significant contributors to classroom discourse. The students were encouraged to reach conclusions based on relevant information they acquired on their own, instead of relying on the teacher. The teacher recognized the students' personal perspectives on the issue, and new dimensions of the issue of climate change that the students brought forward were incorporated into the classroom discourse. On the other hand, the teacher repeatedly adhered to a storyline in which the students were positioned as recipients and as dependent on the teacher. This was manifested in, for example, the teacher providing explanations or directing the students' work.

When integrating SSI into science education, the contrasting storylines can be understood as the manifestation of two discernible tensions between different educational aims. First, there is a tension between the aim of exploring various dimensions of SSI, including students' perspectives, and the aim of conveying specific, predefined content knowledge. Dealing with SSI calls for emphasizing dialogic classroom practices in which multiple sources of knowledge and diverse perspectives on SSI, including students' perspectives, are explored (Ratcliffe and Grace 2003; Zeidler et al. 2005). At the same time, students should be given the opportunity to learn a body of science content knowledge as defined by the national curriculum. In the present study, this tension was played out through the teacher's positioning of the students as either legitimate contributors to the classroom discourse or as recipients. Second, a tension exists between the aim of enhancing the students' independence as learners and the teacher's responsibility to direct the students' activities. The integration of SSI into science education aims to enhance students' independence as learners (Zeidler et al. 2011), which implies increasing the students' responsibility for their own learning activities. Yet, students are dependent on the teacher for guidance because he or she is the more knowledgeable person when it comes to the science content that they are about to learn. Furthermore, the teacher is still highly responsible for directing the students' activities so that they progress towards intended learning goals. In the present study, this tension was manifested in the teacher's positioning of the students as either independent learners or dependent on the teacher.

Earlier research (Bossér et al. 2015) indicates that balancing these educational aims and dealing with these tensions in moment-to-moment classroom interactions with students, is a major challenge for teachers who integrate SSI into their classroom practices. In the area of teaching scientific concepts, Mortimer and Scott (2003) have thoroughly explored the relationships between different educational aims and different approaches to teacher-student interactions in the science classroom. They conclude that efficient teaching of scientific concepts implies moving back and forth between dialogic and authoritative communicative 
approaches in classroom discourse to align with different teaching purposes. The dialogic approach implies paying attention to more than one point of view, including students' views, and this fits with the purpose of engaging students with the content and exploring the students' everyday ideas about a concept. In contrast, the authoritative approach pays attention to only one point of view, in this case, the school science point of view, and this fits with the purpose of introducing and focusing on the scientific meaning of concepts. Mortimer and Scott (2003) do not explicitly discuss student positioning. Nevertheless, we argue that the dialogic and authoritative communicative approaches could be considered analogous to the contrasting storylines in the classroom practice drawn upon by the teacher in the present study. The storyline in which the students were positioned as legitimate contributors to classroom discourse aligns with a dialogic communicative approach, while the storyline in which the students were positioned as recipients aligns with an authoritative approach.

It is important to note that the integration of SSI into science education ultimately aims to prepare students for participation in informed decision-making on SSI. The accomplishment of this overarching goal requires supporting students' development of scientific content knowledge, but equally important, empowering students in terms of enhancing their independence as learners and positioning them as legitimate participants in discussions and decision-making on SSI. Consequently, when integrating SSI into classroom practice, it is crucial that teachers specifically consider how to balance contrasting storylines to promote this overarching goal. In the present study, when the students expressed uncertainty regarding the scientific meanings of concepts, the teacher adhered to a storyline in which the students were positioned as recipients, which fits with the purpose of promoting the students' learning of scientific content. However, when the students asked the teacher to make decisions for them, the teacher adopted a storyline in which the students were positioned as responsible for reaching their own conclusions. This storyline fits with the purpose of enhancing the students' independence as learners. We suggest that the descriptions provided in the present study, of how the teacher's interactions with the student made available different positions for the students as participants in the classroom, enhance our knowledge of the ways in which teachers can promote certain aims relevant to preparing students for participation in informed decision-making on SSI.

\section{Storylines Regarding Students as Participants Adhered to by the Students}

In the present study, there was no evidence of the students challenging the storyline in which they were positioned as dependent on the teacher. We interpret this as the students being comfortable with this storyline. One reason for this might be that they are familiar with this storyline due to previous experience and history in the school setting, because research has shown that there is a prevalence of transmissive pedagogy in science education that positions the teacher as a conveyor of knowledge (Lemke 1990; Newton et al. 1999; Osborne et al. 2002; Pimentel and McNeill 2013). The students appeared to be less comfortable with the storyline associated with the implementation of SSI and the advancement of more dialogic classroom practices in which they were positioned as independent learners, which was a new experience to them in the science classroom. This positioning was challenged by several students, a result that supports findings from previous research that shows that students often resist changes in classroom practices (Lemke 1990; Zeidler et al. 2011). Consequently, it is reasonable to suggest that teachers need to be persistent and prepared for resistance from students when transforming classroom practices to which they are accustomed. 
We suggest that one way of reducing resistance and facilitating the students adopting new storylines in the classroom practice is to ensure that the learning goals associated with each learning activity are explicit and shared by the teacher and the students. A number of different learning goals, characterized as conceptual knowledge, procedural knowledge, and attitudes and beliefs, could be defined when dealing with SSI (cf. Ratcliffe and Grace 2003). Conceptual knowledge consists of, for example, understanding relevant science concepts and the principles of scientific inquiry. Procedural knowledge consists of, for example, the ability to evaluate information and to engage in informed decision-making. It is reasonable to expect that students place emphasis on developing conceptual knowledge, as a result of their previous experiences of science education. Therefore, it seems crucial that alternative storylines are intelligible to the students in view of associated learning goals. For example, it has to be communicated to the students that the development of procedural knowledge requires their engagement in the process of decision-making, and that they are not simply served the outcome of the process.

\section{Storylines Relevant to Students' Positions as Participants in Negotiations on SSI}

The teacher-student interactions revealed a number of different storylines which we consider relevant to the positioning of students as participants in this SSI context. These storylines will be discussed in this section. On one hand, the teacher introduced a storyline in which the students were positioned as members of society who share the responsibility for the causes of climate change and for taking action in response to it. This storyline provided opportunities for the students to personally engage with the issue. Several students voiced personal concerns, for example, how they might personally suffer from the consequences of climate change. This result is in line with previous research, which shows that personal concerns are important for many people when dealing with SSI (Bell and Lederman 2003; Byrne et al. 2014; Patronis et al. 1999; Sadler and Zeidler 2004). On the other hand, the teacher positioned the students as spectators to societal debate and decision-making on SSI, by positioning experts and authorities as the agents responsible for change. In view of the students' personal engagement with the issue, we consider the positioning of students as spectators problematic, because it entails the students not being equipped to take action in response to issues that concern them. We suggest that the introduction of storylines in which the students are positioned as responsible along with storylines that make available positions for the students as agents, is critical to promote the students' engagement with the issue as well as to empower students. Consequently, it is important to make use of issues that offer the opportunity to introduce such storylines.

Previous research findings based on interviews (Sadler and Zeidler 2004, 2005) and questionnaires (Ojala 2015) show that it is reasonable to expect that students will make emotive considerations and also express emotions in the classroom when they are invited to engage in discussions and decision-making on SSI. It has been stressed that teachers' recognition of negative emotions, such as worry or anger, expressed in the classroom are vital to promote the empowerment of students (Ojala 2015). The present study, performed in a naturalistic setting, provides examples of emotions expressed by students in relation to a specific SSI, and descriptions of the teacher's way of dealing with these. Several students expressed negative emotions, such as anxiety and frustration, related to the issue of climate change. The results suggest that one way for the teacher to recognize such negative emotions is to relieve them by focusing the attention on positive societal development and efforts made by experts and politicians in response to the SSI. Such recognition of the students' negative emotions aligns with a storyline in which emotions are accepted as a result of engaging with SSI. 
The teacher's recognition of students' emotions, associated with their personal engagement with SSI, is an important step towards the development of classroom practices aimed at positioning the students as legitimate participants in discussions and decision-making on SSI. However, by positioning experts and authorities as the agents who are dealing with the issue, it can be argued that the teacher adopts a storyline in which participation in negotiations on SSI is primarily based on expert knowledge. Thereby, the potential for the students to envision themselves, while not being experts, as participants in negotiations on SSI might be reduced. Moreover, by solely paying attention to positive societal development, it can be argued that the students' views of the situation, for example that "nothing ever gets done" in response to climate change, are dismissed. Consequently, the learning potential from SSI is not fully exploited. Science education scholars have advocated that students' recognition of the complexities of SSI and the various perspectives on the issues are worthwhile learning outcomes when dealing with SSI (Sadler et al. 2007). By overlooking the opportunity to discuss why development is slow or why it is difficult to agree on actions to take, due to, for example, an uncertain knowledge base or various stakeholder interests, the complexity of any issue will not be sufficiently explored. We, therefore, suggest that it would be beneficial to use the emotions expressed by the students in relation to an SSI as a starting point for such discussions in order to manifest the legitimacy of the emotions, as well as the specific knowledge related to the issue, and to fully exploit the learning potential from SSI. In this way, the engagement that the students have shown might be retained while providing them with opportunities to develop knowledge vital for taking part in discussions and decisionmaking on SSI.

\section{Conclusion}

Even though only two lessons with one and the same teacher and his students were analysed in the present study, we argue that the results provide knowledge relevant to the integration of SSI into science education. By using positioning theory to analyse moment-to-moment teacherstudent verbal interactions regarding a SSI, it was possible to uncover the ways in which the teacher's interaction with the students made available or promoted different student positions, that is, different parts for the students to play, as participants, when dealing with SSI in the classroom. Hence, we argue that the use of positioning theory as an analytical framework has the potential to provide knowledge of the ways in which teacher-student interactions set conditions for the empowerment of students in the context of SSI-based education. Such knowledge is important for the advancement of dialogic classroom practices in which students are positioned as independent learners and as legitimate participants in discussions and decision-making on SSI. We therefore suggest that one perspective for further research is to use positioning theory to analyse larger samples involving different teachers and student groups. In this way, it could be possible to uncover how a wider variety of student positions can be promoted through classroom discourse when dealing with SSI.

The results show that when dealing with SSI, various storylines are drawn upon in teacherstudent interactions that make available different positions for the students as participants in the classroom and in negotiations on SSI. Consequently, teachers must successfully balance different storylines in order to promote the achievement of the educational outcomes relevant to the overarching aim of positioning students as legitimate participants in discussions and decision-making on SSI. For example, the results suggest that storylines in which the students 
are positioned as members of society concerned with SSI provide opportunities for the students to personally engage with SSI. At the same time, storylines that position the students as spectators by positioning experts as agents responsible for change risk undermining students' empowerment. We therefore suggest that it is important to make use of issues that offer opportunities to introduce storylines in which the students are positioned as members of society who are concerned with SSI, along with storylines that make available positions for the students as agents in relation to SSI.

Moreover, when students personally engage with SSI, teachers have to be prepared to deal with students' expressions of negative emotions. The results show that one way for the teacher to deal with negative emotions expressed in the classroom in relation to SSI is to focus the attention on positive societal development and efforts made in response to SSI. However, we suggest that it would be more beneficial to use the emotions expressed by the students as a starting point for exploring the complexities of SSI. In this way, the students will be positioned as legitimate participants in discussions and decision-making on SSI owing to their emotional involvement with the issue, irrespective of their lack of expert knowledge.

Acknowledgements The authors would like to acknowledge the teacher and the students who participated in and made this study possible. The authors would also like to thank the reviewers for their valuable comments on earlier versions of this paper. The research was financially supported by The Swedish Research Council VRUVK (721-2011-5534); The Faculty of Health and Life Sciences, Linnaeus University and The Board of Teacher Education, Linnaeus University.

Open Access This article is distributed under the terms of the Creative Commons Attribution 4.0 International License (http://creativecommons.org/licenses/by/4.0/), which permits unrestricted use, distribution, and reproduction in any medium, provided you give appropriate credit to the original author(s) and the source, provide a link to the Creative Commons license, and indicate if changes were made.

\section{References}

Aikenhead, G. S. (2006). Science education for everyday life: evidence-based practice. New York: Teachers College Press.

Almahrouqi, A., \& Scott, P. (2012). Classroom discourse and science learning. Science Education Research \& Practice in Europe, 291.

Bell, R. L., \& Lederman, N. G. (2003). Understandings of the nature of science and decision making on science and technology based issues. Science Education, 87(3), 352-377.

Bossér, U., Lundin, M., Lindahl, M., \& Linder, C., (2015). Challenges faced by teachers implementing socioscientific issues as core elements in their classroom practices. European Journal of Science and Mathematics Education, 3(2), 159-176.

Bryce, T., \& Gray, D. (2004). Tough acts to follow: the challenges to science teachers presented by biotechnological progress. International Journal of Science Education, 26(6), 717-733.

Byrne, J., Ideland, M., Malmberg, C., \& Grace, M. (2014). Climate change and everyday life: repertoires children use to negotiate a socio-scientific issue. International Journal of Science Education, 36(9), 1491-1509.

Chin, C. (2006). Classroom interaction in science: teacher questioning and feedback to students' responses. International Journal of Science Education, 28(11), 1315-1346.

Davies, B., \& Harré, R. (1990). Positioning: the discursive production of selves. Journal for the Theory of Social Behaviour, 20(1), 43-63.

Dawson, V. M., \& Venville, G. (2008). Teaching strategies for developing students' argumentation skills about socioscientific issues in high school genetics. Research in Science Education, 40(2), 133-148.

Fowler, S. R., Zeidler, D. L., \& Sadler, T. D. (2009). Moral sensitivity in the context of socioscientific issues in high school science students. International Journal of Science Education, 31(2), 279-296.

France, B., Mora, H. A., \& Bay, J., L. (2012). Changing perspectives: Exploring a pedagogy to examine other perspectives about stem cell research. International Journal of Science Education, 34(5), 803-824. 
Frijters, S., ten Dam, G., \& Rijlaarsdam, G. (2008). Effects of dialogic learning on value-loaded critical thinking. Learning and Instruction, 18, 66-82.

Hand, M., \& Levinson, R. (2012). Discussing controversial issues in the classroom. Educational Philosophy and Theory, 44(6), 614-629.

Harré, R., \& Moghaddam, F. (2003). Introduction: The self and others in traditional psychology and in positioning theory. In R. Harré \& F. Moghaddam (Eds.), The self and others: positioning individuals and groups in personal, political, and cultural contexts (pp. 1-11). Westport, CT: Praeger Publishers/Greenwood Publishing Group.

Harré, R., \& van Langenhove, L. (1999). Positioning theory: moral contexts of intentional action. Oxford; Malden, Mass: Blackwell.

Harris, R., \& Ratcliffe, M. (2005). Socio-scientific issues and the quality of exploratory talk-What can be learned from schools involved in a "collapsed day" project? Curriculum Journal, 16(4), 439-453.

Jenkins, E. W. (2006). The student voice and school science education. Studies in Science Education, 42(1), 49-88.

Klosterman, M. L., \& Sadler, T. D. (2010). Multi-level assessment of scientific content knowledge gains associated with socioscientific issues-based instruction. International Journal of Science Education, 32(8), 1017-1043.

Kyriacou, C., \& Issitt, J. (2008). What characterises effective teacher-initiated teacher-pupil dialogue to promote conceptual understanding in mathematics lessons in England in Key Stages 2 and 3: a systematic review. Technical report. Research Evidence in Education Library. London.

Lee, H., Yoo, J., Choi, K., Kim, S.-W., Krajic, J., Herman, B. C., \& Zeidler, D. L. (2013). Socioscientific issues as a vehicle for promoting character and values for global citizens. International Journal of Science Education, 35(12), 2079-2113.

Lemke, J. L. (1990). Talking science: language, learning, and values. Norwood, N. J: Ablex.

Levinson, R. (2004). Teaching bioethics in science: crossing a bridge too far? Canadian Journal of Science. Mathematics and Technology Education, 4(3), 353-369.

Lyons, T. (2006). Different countries, same science classes: students' experiences of school science in their own words. International Journal of Science Education, 28(6), 591-613.

Mork, S. M. (2005). Argumentation in science lessons: focusing on the teacher's role. NorDiNa, 1(1), 17-30.

Mortimer, E. F., \& Scott, P. (2003). Meaning making in secondary science classrooms. Maidenhead; Philadelphia: Open University Press.

Newton, P., Driver, R., \& Osborne, J. (1999). The place of argumentation in the pedagogy of school science. International Journal of Science Education, 21(5), 553-576.

Nystrand, M. (1997). Opening dialogue: understanding the dynamics of language and learning in the English classroom. New York: Teachers College Press.

Ojala, M. (2015). Hope in the face of climate change: associations with environmental engagement and student perceptions of teachers' emotion communication style and future orientation. Journal of Environmental Education, 46(3), 133-148.

Osborne, J., Duschl, R., \& Fairbrother, R. (2002). Breaking the mould? Teaching science for public understanding. London: Nuffield Foundation.

Östman, L. (1998). How companion meanings are expressed by science education discourse. In D. A. Roberts \& L. Östman (Eds.), Problems of meaning in science curriculum (pp. 54-70). New York: Teachers College Press.

Ottander, C., \& Ekborg, M. (2012). Students' experience of working with socioscientific issues - a quantitative study in secondary school. Research in Science Education, 42(6), 1147-1163.

Patronis, T., Potari, D., \& Spiliotopoulou, V. (1999). Students' argumentation in decision-making on a socioscientific issue: implications for teaching. International Journal of Science Education, 21(7), 745-754.

Pimentel, D. S., \& McNeill, K. L. (2013). Conducting talk in secondary science classrooms: investigating instructional moves and teachers' beliefs. Science Education, 97(3), 367-394.

Ratcliffe, M., \& Grace, M. (2003). Science education for citizenship: teaching socio-scientific issues. Maidenhead; Philadelphia: Open University Press

Ratcliffe, M., \& Millar, R. (2009). Teaching for understanding of science in context: evidence from the pilot trials of the "twenty first century science" courses. Journal of Research in Science Teaching, 46(8), 945-959.

Robson, C. (2011). Real world research: a resource for users of social research methods in applied settings (3rd ed.). Chichester, West Sussex; Hoboken N.J: Wiley-Blackwell.

Sadler, T. D. (2009). Situated learning in science education: socio-scientific issues as contexts for practice. Studies in Science Education, 45(1), 1-42.

Sadler, T. D., \& Zeidler, D. L. (2004). The morality of socioscientific issues: construal and resolution of genetic engineering dilemmas. Science Education, 88(1), 4-27.

Sadler, T. D., \& Zeidler, D. L. (2005). Patterns of informal reasoning in the context of socioscientific decision making. Journal of Research in Science Teaching, 42(1), 112-138. 
Sadler, T. D., Barab, S. A., \& Scott, B. (2007). What do students gain by engaging in socioscientific inquiry? Research in Science Education, 37(4), 371-391.

Scott, P. (1998). Teacher talk and meaning making in science classrooms: a Vygotskian analysis and review. Studies in Science Education, 32, 45-80.

Simon, S., Erduran, S., \& Osborne, J. (2006). Learning to teach argumentation: research and development in the science classroom. International Journal of Science Education, 28(2-3), 235-260.

Skolverket. [The Swedish National Agency for Education.] (2011). Ämnesplan i naturkunskap. [Subject syllabus for the subject science studies.] http://www.skolverket.se/polopoly_fs/1.174557!/Menu/article/attachment/Science\%20 studies.pdf. Accessed 14 February 2014.

Smith, H., \& Higgins, S. (2006). Opening classroom interaction: the importance of feedback. Cambridge Journal of Education, 36(4), 485-502.

Vetenskapsrådet. [The Swedish Research Council.] (2011). God forskningssed. [Good research practice.] https://publikationer.vr.se/produkt/god-forskningssed/. Accessed 8 February 2012.

Wellington, J., \& Osborne, J. (2001). Talk of the classroom: language interactions between teachers and pupils. Language and literacy in science education (pp. 24-40). Buckingham: Open University Press.

Wells, G. (2007). Semiotic mediation, dialogue and the construction of knowledge. Human Development, 50(5), $244-247$.

Wood, L. A., \& Kroger, R. O. (2000). Doing discourse analysis: methods for studying action in talk and text. Thousand Oaks, Calif: Sage Publications.

van Zee, E., \& Minstrell, J. (1997). Using questioning to guide student thinking. Journal of the Learning Sciences, 6(2), 227-269.

Zeidler, D. L. (2003). The role of moral reasoning on socioscientific issues and discourse in science education. Doredrecht: Kluwer Academic Publishers.

Zeidler, D. L., Sadler, T. D., Simmons, M. L., \& Howes, E. V. (2005). Beyond STS: a research-based framework for socioscientific issues education. Science Education, 89(3), 357-377.

Zeidler, D. L., Applebaum, S. M., \& Sadler, T. D. (2011). Enacting a socioscientific issues classroom: transformative transformations. In T. D. Sadler (Ed.), Socio-scientific issues in the classroom (pp. 277305). New York: Springer. 